\title{
A DESCRIPTIVE ANALYSIS OF THE USE OF NUMERICAL MORPHEME, “EKg” (ONE) BY THE NATIVE AND NON-NATIVE SPEAKERS OF SINHALA
}

\author{
Nipunika Dilani ${ }^{1}$ \\ Senior Lecturer, \\ Department of English, \\ Buddhist and Pali University of Sri Lanka, \\ Sri Lanka
}

\begin{abstract}
:
"eka" is a numerical morpheme that stands to mean one in English. The term is commonly inserted in mixing English codes in speaking in the native language of Sinhala in Sri Lankan society. However, the insertion of the term is complicated because it is governed by descriptive grammar rules. Thus, the current study analysed the acquisition of the use of the morpheme, "eka" by native speakers and non-native speakers of Sinhalese. The study can be categorized under qualitative approach for which the primary data was collected from two native speakers and two non-native speakers of Sinhala through semi-structured interviews and observation of natural speech. The data has been analysed descriptively and comparatively referring to mental rules regarding the usage of the term. The study found that non- native speakers of Sinhala fail to acquire the complete manipulation of the term and it is suggested that they use it as a flexible term that fits into different contexts.
\end{abstract}

Keywords: code switching, ekə, native speakers, non-native speakers, Sinhala

\section{Introduction}

Code mixing that normally takes place between or within sentences involving words, phrases or sometimes parts of words (Spolsky, 2004) is identified as a common practice in Sri Lankan linguistic context (Senaratne, 2009; Shashikala, 2021; Mawelle, 2019). Being both multilingual and historically post-colonial the native languages of Sinhalese and Tamil constantly interact with English which results in mixing English codes with native languages. The process of mixing codes has exercised different strategies particularly in order to normalize and naturalize the mixed language. Among different strategies the use of Sinhalese nominalizer "eka" has become an essential term in the bilingual discourse of mixing English codes. "eka" is a numerical morpheme that stands to mean one in English.

${ }^{1}$ Correspondence: email nipunika@bpu.ac.lk 
Controversies regarding code switching in the Sri Lankan society can be observed between the linguists and the lay people. While linguists identify code switching as an index of bilingual proficiency laypeople particularly see it as a part of language degeneration (Bullock, B., \& Toribio, 2009). According to them, the reason for this disparity is rooted on grammar. The common people understand language prescriptively whereas linguists who study language objectively are more interested in descriptive grammar that deals with unconscious knowledge in deciding linguistic behaviour (ibid). As a result, the speakers' mental lexicon plays a major role in the process of accurate blending codes of two languages. Accordingly, this study tries to discover mental rules regarding the use of morpheme, "ekz" in mixing English codes in the Sinhalese language while comparing how native and non-native users of Sinhala employ those mental rules in the speaking discourse.

\section{Research Questions}

The current study tries to answer two main research questions.

1) What are the mental rules governing the use of "ekə"?

2) How do the mental rules related to the use of "eka" differ from native speakers of Sinhalese to non-native speakers of Sinhalese?

\section{Literature Review}

This section focuses on an analysis of general insights to code switching followed by a general survey of the literature of the research on the topic under discussion.

In the interaction of two or more languages, different changes in the native language and its linguistic behaviour can occur at different levels. Code mixing, code switching and hybridization are some common practices that make certain alterations to the native languages. This situation is witnessed to a greater degree in multi-lingual societies where non-native varieties of English function as a second language (Bernhardt \& Davis, 2007). When the English speakers come into contact with vernacular culture and language, if a native word is not available or they are unaware of a term, they tend to use a mixed code. And then sometimes such patterns get established too. Or else the native speakers also tend to use mixed codes may be out of reasons like social status, easy communication, attitudinal aspects and poor vocabulary. This is known as "indigenization" (Moag \& Moag, 1977) or "nativization" (Kachru, 1978). Indigenization or nativization operates as an adaptation particularly in the speech deriving a colloquial variety (Anwar, 2020).

According to Muysken's typology (Muysken, 2004) three strategies of mixing as alteration, insertion, and congruent lexicalization help in nativization process. All these three strategies are connected in the way that insertion of new items can lead to congruent lexicalization creating alterations with set phrases or expressions in different patterns in the new language. In Sinhalese when insertion of an English word one interesting Sinhalese morpheme, "eka" is mostly followed in order to nativilize the insertion. Thus, the use of "eka" in Sri Lankan context can be vividly explained under the theoretical framework of Muysken's typology. 
The researchers have found interesting facts related to the behaviour of this term in different contexts. The construction of nouns followed by "eka" can be seen in colloquial monolingual utterances (Senaratne, 2009). Gunersekara introduces this morpheme as a "loose" practice due to its constant usage in different contexts(cited in Senaratne, 2009). Senaratne referring to literature concludes (Weerakoon, 1988 cited in Senaratne, 2009) that "eka" behaves as a nominalizer and a complementizer in Sinhala. She further mentions that it occurs in a noun phrase both intransitive and intransitive positions as well as in abstract sense in colloquial Sinhalese. She further referred to data confirming that "eka" occurs only with inanimate nouns when used with English. The current study majorly focuses on this use of "ekə". Studying colloquial Sinhala as a mixed discourse Dissanayake (Dissanayake, 2020) also shows that "eka" has been used in the nativilization process. He identifies it as a suffix that facilitates in creating a compound containing one part in Sinhala and the other in English. Another sociological discourse analysis done by Shashikala (2021) discusses how "eka" functions in spoken discourses. She also confirms that it is used by Sinhala-English bilinguals in spoken discourse after English inanimate nouns only.

The survey of literature makes it evident that the researchers have analysed the use of "eka" in different syntactic and morphological environments. Most of them agree that this code functions as a nativilizer and complementizer in mixing English codes. Sinhalization is the commonest function as many researchers agree upon. Further, they have mentioned that the term is used only with inanimate nouns. However, the current researcher has observed that in addition to the above instances non-native speakers of Sinhala use the term on other occasions and that is interesting and needs further investigation. Not only that, the literature survey made it evident that a comparative study of the acquisition of the term by native and non-native speakers of Sinhalese is hardly found. In this manner, the current study contributes to fill up a long-existed research gap.

\section{Methodology}

The current research belongs to the qualitative approach that produces descriptive data based on spoken words, written documents or observable behaviour (Talylor et al., 2016). Qualitative studies follow a flexible research design especially because the research objectives and the scope may change depending on the data in the middle of the study(Marshall \& Rossman,2011 cited in (Talylor et al., 2016). Under the qualitative approach the current study fits into descriptive research that aims to describe a phenomenon and its characteristics (ibid). Accordingly, the current phenomenon of focus is how the use of the morpheme "eka" is acquired by native speakers of Sinhalese and non-native speakers of Sinhalese. The primary data for the study has been collected through interviews from two non- native speakers of Sinhala and two native speakers of the same age. The two non-native speakers of Sinhala whose mother tongue is Nepali have started to study Sinhala at the age of 13 and 11 respectively when they came to Sri Lanka for studies and now, they have been using Sinhalese for more than 15 years as the dominant language. They have studied in Sinhala medium up to Advanced Level and now as undergraduates of the same batch, all four participants study in English medium. In that sense, 
the four participants show almost similar characteristics in their linguistic behaviour except for the difference in mother tongues. The researcher selected this sample purposefully based on the similar characteristics their share. In addition to the semi-structured interviews, natural language produced by the non-native speakers of Sinhalese was observed and notes were taken down for about a period of two months. The data analysis involved an inductive exploration of the data identifying recurring themes, patterns, and concepts followed by an interpretation and description of those categories. Further, the data was analysed using comparative methods whenever necessary.

\section{Findings and Discussion}

Following table shows a summary of the significant data collected from natural conversations and interviews. The data has been tabulated into themes as below for the purpose of analysis.

Table 1: Data from natural speech

\begin{tabular}{|c|c|}
\hline Non-native Speakers of Sinhalese & Native Speakers of Sinhalese \\
\hline \multicolumn{2}{|l|}{ With English Nouns } \\
\hline phone eka & phone $e k a$ \\
\hline Wifi eka & Wifi \\
\hline TV eka & TV eka \\
\hline bus eka & bus eka \\
\hline bill eka & bIla \\
\hline \multicolumn{2}{|l|}{ With Sinhala Inanimate Nouns } \\
\hline wı $\theta$ ura ekə (water) & wı $\theta u r a ~ e k a$ \\
\hline j $\Lambda$ Ura ekə (key) & 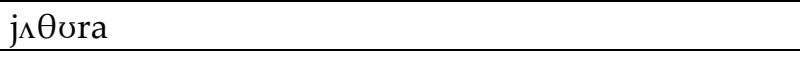 \\
\hline sereppu eka (slippers) & sereppu ðeka \\
\hline sulli eka (money) & sullI \\
\hline \multicolumn{2}{|l|}{ With Adjectives } \\
\hline usa eka (tall one/thing) & usa eka \\
\hline k^lv ekə (black one/thing) & k৯lveka \\
\hline lıssanəmə ekə (beautiful one/thing) & lıssanama eka \\
\hline \multicolumn{2}{|l|}{ With Verbs } \\
\hline kınə eka (eating) & kınə eka \\
\hline bona eka (drinking) & bona eka \\
\hline liyınə eka (writing) & liyına eka \\
\hline \multicolumn{2}{|l|}{ Utterances } \\
\hline $\Lambda$ ra j $\Lambda$ Ura ekə denna (Give me that key) & $\Lambda$ ra j $\Lambda$ Өra denna (Give that key) \\
\hline $\begin{array}{l}\text { m^ge kınna:dI ekə ðenne neðða? (Don't you give my } \\
\text { spectacles?) }\end{array}$ & $\begin{array}{l}\text { m^ge k^nna: dIja ðenne neðða? (Don't you give my } \\
\text { spectacles?) }\end{array}$ \\
\hline 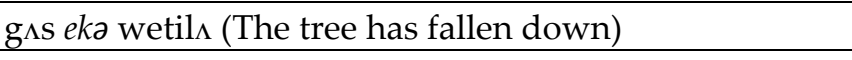 & 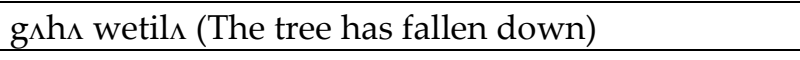 \\
\hline msl watti eka ðenna (Give me the tray/basket of flower) & $\mathrm{m} \wedge \mathrm{l}$ wsttija ðenna (Give me the \\
\hline 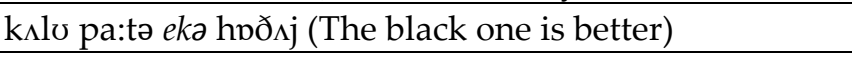 & kılu pa:tə ekə h pð $\Lambda \mathrm{j}$ (The black one is better) \\
\hline Saree $e k \partial l_{\Lambda s s a n} \wedge$ (The saree is beautiful) & Sareeja $1_{\Lambda s s a n \wedge j}$ (The saree is beautiful) \\
\hline
\end{tabular}




\subsection{With English Nouns}

The research found some interesting facts regarding the mental grammar related to "eka". The previous research has concluded that "eka" has been used as a morpheme that helps in creating material nouns especially as a noun ending particle(suffix) related to borrowed words from English as a strategy of Sinhalization (Senaratne, 2009; Dissanayake, 2020; Shashikala, 2021). It was evident that "eka" is found in use as a recent development in colloquial Sinhalese after colonization. The nouns ending in consonants which are rare among original Sinhalese nouns found to be difficult to pronounce by native Sinhala speakers (Gamage, 2020). It is clear in the above data set collected from the native speakers of Sinhala that in cases where borrowed words end in a consonant or a consonant sound like bus, car, TV, phone, fridge, etc, "eka" follows the word. In such cases "ekə" has been adopted as a noun ending suffix in order to make the pronunciation of such words smooth in addition to Sinhalization. However, in the example of Wifi the natives don't add "eka" whereas the non-natives add "ekz". The interview further confirmed that the common words like signal and Bluetooth even though ending in a consonant do not take "eka" in native speech. The reason could be counted on the uncountabiliy and the countability of the nouns. As these nouns are uncountable, even though they end with a consonant, pronounced without "eka". An utterance of the nature is;

\section{(a) Wifi on karanna. (Please switch on Wifi)}

However, despite non-native speakers of Sinhala also having acquired this common rule, use "eka" with all English words irrespective of the distinction between countable and uncountable nouns. The above utterance is made by non-native speakers of Sinhala as;

(b) Wifi eka on karanna. (Please switch on Wi-Fi)

Before the recent hybridization of language, the existed rule in Sinhala is adding of suffix "aja" to decline nouns and it has been taken up to decline borrowed nouns as "bısaja" (a bus) and "ca:raja" (a car) as an attempt of Sinhalization or naturalization of such noun declension (ibid). Even though this assimilation has failed in cases like the above which are now limited to formal written discourse, has been successful in some cases as below.

(c) Order + aja> s:daraja (the order)

Tractor + aja $>$ træktəraja or sometimes in rural colloquial usage as tæktərəjə (a tractor)

Lorry+ aja>lorIja (the Lorry)

Saree+ aja>sa:rlja (the saree)

In the above examples(c), in spite of some consonant endings, the rule has been naturally assimilated to pronounce them with a vowel ending by adding "əjə". An exception to the above (c) can be seen among the native speakers in the use of an English word like bill. It is declined as, bill + a $>$ bIla in a similar way to the natural Sinhalese way of adding the suffix " $a$ " to form singular as in; 
(d) $m \wedge l+\partial>m \wedge l \partial$

mol+a> molə

$\mathrm{g}_{\Lambda} \mathrm{l}+\mathrm{\partial}>\mathrm{g} \Lambda \mathrm{l}$

In this case, the non-native speakers have failed to grasp this singularization process and there also they use "eka" as;

(e) bill+eka> bill eka

gıs +eka > gıs eka

However, the non-native speakers have not acquired the rule related "aja" in place of "ekə" as natives use in the above examples (c). In all the instances they use "eka" as in;

(f) Order + eka $>$ s:dara eka (the order)

Tractor + eka $>$ trækta eka (the tractor)

Lorry+ eka >lorI eka (the Lorry)

Saree+ eka >sa:rI eka (the saree)

One common utterance they make is, sa:rI eka lassaj ms.(Miss, the saree is beautiful). Moreover, the collected data indicates another mental rule formed by the native speakers. They use "eka" not only with English borrowings but also with uncountable Sinhala nouns when using in the countable form. This is quite similar to the English usage of uncountable nouns as countable nouns.

Example:

A glass of water

A bottle of sugar

A pair of sandals

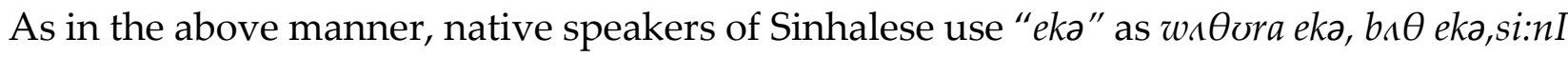
eka, etc, for the same purpose.

In the comparison of the above declension rules used by the native speakers of Sinhala with the non-native speakers of Sinhalese, some inconsistencies in usage could be seen. They also use "eka" with English words as the native speakers do but they overgeneralize the rule with certain Sinhalese words. Some examples are as;

(g) gis eka (a tree)

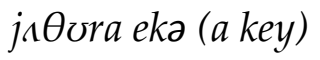

salli eka(money)

kınna:dI eka (a pair of spectacles) 
The native speakers never use "ek $ə$ " with native Sinhalese words as in instances above $(g)$. However, in the way the non-native speakers abundantly use it with different contexts without having a proper pattern, I feel that for them "eka" stands a "loose" term that is inserted constantly to streamline the use of their non-native language. Even though Gunersekara introduces this morpheme as a "loose" practice of native speakers of Sinhala(cited in Senaratne, 2009) due to its constant usage in different contexts, the study finds that native speakers follow a regular pattern whereas non-natives adopt it loosely without adhering to a properly governed rule. For them "eka" seems to be a highly flexible term that is inserted in many contexts especially when they get stuck to complete an utterance.

Likewise, it seems that their mental grammar hasn't been developed to the level of the native speakers in order to comprehend the intricate rules of using "eka" with consonant and vowel sound endings even though they have been using Sinhala while being in Sri Lanka for more than 15 years. Thus, they not only fail to distinguish between consonant and vowel sound ending rule but also the use of "aja" instead of "eka" in some cases. The way they have acquired has not facilitated them to acquire the true complexity of the use of the term, "eka".

Sometimes, in forming collective nouns the non-native speakers may have been influenced by the English rule which non-native speakers of Sinhala actually learnt prior to learning Sinhalese as in k^nna:dI eka), serepp $v$ ekə in an analogous way to "a pair of spectacles" and "a pair of sandals" taking them as single units in contrast to the native speakers' using them as kınna:dI ðeka (sometimes kınna:dIja/kınna:dI ku:ttama)(two spectacles) and sereppo dekə(two slippers).

"eka" which was basically developed as a suffix for the material noun endings, was later on naturally expanded to be used with other word classes like adjectives and verbs too. The use of the morpheme with adjectives and verbs proves less complicated than with nouns. And thus, no difference in use was found between the native and non-native speakers of Sinhala.

\section{Conclusion}

This descriptive analysis reveals the complexity of mental grammar related to the morpheme, "ek ${ }^{\prime}$ " in the Sinhalese language particularly in comparison with its acquisition by native speakers and non-native speakers. The data as well as the literature explicate that "eka" plays a dominant role in the spoken discourse especially when English codes are switched into the Sinhala language. It plays a major role in the Sinhalization process of non-native codes. However, this process is rule-governed. It is used with inanimate nouns only by both native and non-native speakers of Sinhalese. Further, the native speakers add the term with consonant nouns only in order to smooth the pronunciation. But the non-native speakers fail to acquire this rule and they use "eka" with both consonant and vowel ending English words. Moreover, native speakers use it, particularly with countable nouns. Unlike the native speakers, non-native speakers haven't grasped the distinction of using it only with countable nouns. They don't show these discrepancies in the use of the term. In conclusion, the use of "eka" is highly complex that the non-native speakers in the current study those who have been using Sinhalese for more than at 
least 15 years by living in the Sinhalese society and studying in Sinhala medium, have failed to acquire the complete convention of use of the term "ekə" in speech discourse of Sinhala.

\section{Conflict of Interest Statement}

The author declares no conflicts of interests.

\section{About the Author}

Dr. Nipunika Dilani is a senior lecturer at the Department of English of the Buddhist and Pali University of Sri Lanka. Her research interests include English literature, Linguistics, Buddhism and Comparative Studies.

\section{References}

Anwar, B. (2020). Indigenization in Multilingual Setting: Evidence from Pakistan English Written Discourse. Pakistan Social Sciences Review, 4(1), 65-78. https://doi.org/10.35484/pssr.2020(4-i)06

Bernhardt, K., \& Davis, G. (Eds.). (2007). Lingua et Linguistica 1.2. https://books.google.lk/books?hl=en\&lr=\&id=72wo1wtuWtUC\&oi=fnd\&pg=PA109\&dq= code+mixing + in + multilingual + societies\&ots $=\mathrm{A}-$

jDthIuNt\&sig=mNmyvMsIUU_QALOsIY3-liG8H04\&redir_esc=y\#v=onepage\&q\&f=false

Bullock, B., \& Toribio, A. (2009). Themes in the study of code-switching. In B. \& A. Toribio (Ed.), The Cambridge Handbook of Linguistic Code-switching (pp. 1-18). Cambridge University Press. https://doi.org/doi:10.1017/CBO9780511576331.002

Dissanayake, S. (2020). Colloquial Sinhala language as a mixed discourse variety; a study on the syntactic and semantic impact of English language on present day colloquial Sinhala language. https://doi.org/DOI:10.13140/RG.2.2.21123.73764

Mawelle, I. J. (2019). New Dimensions in Code-Mixing and the Sri Lankan Case: An Exploratory Study. Colombo Journal of Multi-Disciplinary Research, 4(1), 133. https://doi.org/10.4038/cjmr.v4i1.39

Muysken, P. (2004). Bilingual Speech, A typology of code mixing. Cambridge University Press. https://books.google.lk/books?id=1JI7qrIKmokC\&printsec=frontcover\&dq=muysken+typ ology+alteration.+insertion\&hl=en\&sa $=X \& v e d=2 a h U K E w i r-$ amF9sP0AhVpUGwGHWgiBvMQ6AF6BAgEEAI\#v=onepage\&q\&f=false

Senaratne, C. D. (2009). Sinhala-English code-mixing in Sri Lanka: a sociolinguistic study. In Lot (Issue 217).

Shashikala, H. P. L. W. (2021). Exploring the Sociolinguistic Aspects of Sinhala-English CodeMixing among Urban Sri Lankan Bilingual Speakers. Open Journal of Modern Linguistics, 11(02), 158-173. https://doi.org/10.4236/ojml.2021.112014

Spolsky, B. (2004). Sociolinguistics (W. H, G (Ed.); fifth). Oxford University Press. https://books.google.lk/books?id=diwosITLKwAC\&pg=PA49\&dq=code+mixing\&hl=en 
\&sa=X\&ved=2ahUKEwiq0Ibeob30AhW5klYBHVVxACoQ6AF6BAgFEAI\#v=onepage\&q $=$ code mixing $\& \mathrm{f}=$ false

Talylor, S. J., Bogdan, R., \& Vault, M. L. De. (2016). Introduction to Qualitative research methods-A guidebook and resource. John Wiley \& Sons. https://books.google.lk/books?id=pONoCgAAQBAJ\&printsec=frontcover\&dq=qualitati ve+research\&hl=en\&sa=X\&ved=2ahUKEwiugITJr7_0AhUpSGwGHReUAHUQ6AF6BA $\mathrm{gFEAI} \# \mathrm{v}=$ onepage $\& \mathrm{q}=\mathrm{qualita}$ tive research $\& \mathrm{f}=$ false

Upul, U. P. (2020). The Influence of English Language on Modern Colloquial Sinhala with Special Reference to Lexical Items (Unpublished PhD dissertation). Buddhist and Pali University of Sri Lanka, Colombo, Sri Lanka. reused under permission of a Creative Commons License. Views, opinions and conclusions expressed in this research article are views, opinions and conclusions of the author(s). and European Journal of Literature, Language and Linguistics Studies shall not be responsible or answerable for any loss, damage or liability caused in relation to/arising out of conflicts of interest, copyright violations and inappropriate or inaccurate use of any kind content related or integrated into the research work. All the published works are meeting the Open Access Publishing requirements and can be freely accessed, shared, modified, distributed and used in educational, commercial and non-commercial purposes under a Creative Commons Attribution 4.0 International License (CC BY 4.0). 